\title{
A Partially Protective Vaccine for Fasciola hepatica Induced Degeneration of Adult Flukes Associated to a Severe Granulomatous Reaction in Sheep
}

\author{
Verónica Molina-Hernández ${ }^{1}{ }^{\mathbb{D}}$, María T. Ruiz-Campillo ${ }^{1}$, Francisco J. Martínez-Moreno ${ }^{2, *}{ }^{\mathbb{C}}$, Leandro Buffoni ${ }^{2}{ }^{(\mathbb{D}}$, \\ Álvaro Martínez-Moreno ${ }^{2}$, Rafael Zafra ${ }^{2}$, María J. Bautista ${ }^{1}$, Alejandro Escamilla ${ }^{3}{ }^{\circledR}$, Raúl Pérez-Caballero ${ }^{2}$ \\ and José Pérez ${ }^{1}$
}

check for

updates

Citation: Molina-Hernández, V; Ruiz-Campillo, M.T.; Martínez-

Moreno, F.J.; Buffoni, L.; Martínez-

Moreno, Á.; Zafra, R.; Bautista, M.J.; Escamilla, A.; Pérez-Caballero, R.;

Pérez, J. A Partially Protective

Vaccine for Fasciola hepatica Induced

Degeneration of Adult Flukes

Associated to a Severe

Granulomatous Reaction in Sheep.

Animals 2021, 11, 2869. https://

doi.org/10.3390/ani11102869

Academic Editor: Christian

Matthias Bauer

Received: 17 September 2021

Accepted: 27 September 2021

Published: 30 September 2021

Publisher's Note: MDPI stays neutral with regard to jurisdictional claims in published maps and institutional affiliations.

Copyright: (C) 2021 by the authors. Licensee MDPI, Basel, Switzerland. This article is an open access article distributed under the terms and conditions of the Creative Commons Attribution (CC BY) license (https:/ / creativecommons.org/licenses/by/ $4.0 /)$.
1 Departamento de Anatomía y Anatomía Patológica Comparadas y Toxicología, Facultad de Veterinaria, Universidad de Córdoba, Edificio de Sanidad Animal, Campus de Rabanales, Ctra. Madrid-Cádiz Km 396, 14014 Córdoba, Spain; b62mohev@uco.es (V.M.-H.); v42rucam@uco.es (M.T.R.-C.); mjbautista@uco.es (M.J.B.); an1pearj@uco.es (J.P.)

2 Departamento de Sanidad Animal (Parasitología), Facultad de Veterinaria, Universidad de Córdoba, Edificio de Sanidad Animal, Campus de Rabanales, Ctra. Madrid-Cádiz Km 396, 14014 Córdoba, Spain; h12bupel@uco.es (L.B.); amm@uco.es (Á.M.-M.); Rafael.zafra@uco.es (R.Z.); raulpc.vetpares@gmail.com (R.P.-C.)

3 Departamento de Fisiología Humana, Histología Humana, Anatomía Patológica y Educación Físico Deportiva, Facultad de Medicina, Boulevard Louis Pasteur, 32, 29071 Málaga, Spain; jandromilla@uma.es * Correspondence: fjmartinez@uco.es; Tel.: +34-9-5721-8721

Simple Summary: Fasciolosis is a parasitic disease of livestock causing important economic losses worldwide and it is also a zoonosis. Current therapy relies on the use of anthelmintic drugs, which is no longer sustainable due to the increase of anthelmintic resistance and the risk of drug residues in food. A deep understanding of the host-parasite interaction is required to develop protective vaccines for the control of fasciolosis. The aim of the present study is to evaluate the hepatic lesions in sheep vaccinated with a partly protective vaccine for F. hepatica, a non-protective vaccine and an infected control group. The protective vaccine showed less severe hepatic lesions than the infected control group. In addition, in the protective vaccine group dead flukes surrounded by a severe granulomatous inflammation were observed, which taken together with the lower fluke burden, suggests that the host response induced by the partially protective vaccine may have been involved in the death of adult flukes of F. hepatica. This is the first study reporting the presence of degenerated flukes associated to a severe granulomatous inflammation in bile ducts in a vaccine trial, a finding that would be useful for improving vaccine efficacy in future trials.

Abstract: Fasciolosis is an important economic disease of livestock. There is a global interest in the development of protective vaccines since current anthelmintic therapy is no longer sustainable. A better knowledge of the host-parasite interaction is needed for the design of effective vaccines. The present study evaluates the microscopical hepatic lesions in sheep immunized with a partially protective vaccine (VAC1), a non-protective vaccine (VAC2), and an infected control group (IC). The nature of granulomatous inflammation associated with degeneration of adult flukes found in the VAC1 group was characterized by immunohistochemistry. Hepatic lesions (fibrous perihepatitis, chronic tracts, bile duct hyperplasia, infiltration of eosinophils and lymphocytes and plasma cells) were significantly less severe in the VAC1 group than in the IC group. Dead adult flukes within bile ducts were observed only in the VAC1 group and were surrounded by a severe granulomatous inflammation composed by macrophages and multinucleate giant cells with a high expression of lysozyme, CD163 and S100 markers, and a low expression of CD68. Numerous CD3+ T lymphocytes and scarce infiltrate of FoxP3+ Treg and CD208+ dendritic cells were present. This is the first report describing degenerated flukes associated to a severe granulomatous inflammation in bile ducts in a F. hepatica vaccine trial. 
Keywords: Fasciola hepatica; vaccines; histopathology; immunohistochemistry; sheep

\section{Introduction}

Fasciolosis is a zoonosis caused by the helminth F. hepatica with a significant economic [1] public health importance all over the world and it is considered by the WHO as a re-emerging neglected tropical disease [2]. After the ingestion of the infective form called metacercariae, the pathogenesis of $F$. hepatica involves a pre-hepatic stage starting with the penetration of newly excysted juveniles (NEJs) through the host intestine wall and its migration within the peritoneal cavity. In the hepatic stage of pathogenesis, the NEJs reach and penetrate the liver capsule, and in the parenchyma the parasites move randomly, forming characteristic transects/tunnels and feed on the hepatic cellular components and blood making NEJs growing and developing rapidly. Lately, the parasites enter the bile ducts where they develop into their adult form and start releasing up to 20,000-24,000 eggs per fluke per day. The feeding and migratory activities cause tissue perforation meanwhile the presence of adult flukes within the bile ducts induces a severe chronic cholangitis with erosion and hyperplasia of the biliary epithelium leading to extensive tissue damage [3].

Nowadays, the control of the disease is based on the use of drugs, particularly triclabendazole, which is effective against multiple parasite stages. However, the growing resistance of the parasite to the chemical products and the concerns about chemical residues in food with their detrimental impact on the environment make the development of novel strategies critical that are more effective and sustainable. Thus, vaccines have been highlighted as the most suitable option to deal with the detrimental effects found with the current used chemical therapies [3,4].

However, over the last three decades there has been proposed numerous vaccine candidates and assessed in several animal models such as rats, mice, and rabbits with non-consistent results in ruminants $[5,6]$. The immunomodulatory capacity exerted by F. hepatica is claimed to be the main obstacle to produce an effective vaccine, some new strategies in vaccine development include the identification of protective peptides by mapping B-cell epitopes of immunodominant $F$. hepatica antigens, which has been recently reported in sheep [7] and cattle [8] with promising results.

Moreover, the assessment of vaccine protection is mainly based on parasitological and systemic immunological parameters. However, up to the date, the liver damage and local immune response is not a relevant parameter to assess the effectiveness of the vaccines against liver flukes and it could be a potent tool to complement the parasitological and serological studies carried out routinely in these vaccine trials. Furthermore, few studies have described the liver pathology in vaccine trials conducted in the natural hosts $[9,10]$.

Based on these premises, we consider the reduction in the liver damage as a crucial feature to evaluate the vaccine effectiveness against $F$. hepatica taking into account that a reduction of the liver damage can be beneficial for the animal welfare and the improvement of the animal production, hence reducing the economic impact of the disease. The aim of the present study was to evaluate the microscopical hepatic damage from sheep immunized with a partly protective vaccine composed of four recombinant proteins from $F$. hepatica in adjuvant Montanide $61 \mathrm{VG}$, a non-protective vaccine composed of the same antigens in adjuvant Alhydrogel and an infected control group of sheep experimentally infected with F. hepatica. Granulomatous cholangitis associated to dead parasites found in sheep immunized with the protective vaccine were characterized using immunohistochemistry. 


\section{Materials and Methods}

\subsection{Experimental Design}

Thirty-seven 8-month-old male Merino-breed sheep obtained from a liver fluke-free farm were used in this study. Before starting the experiment, the animals were treated with fenbendazole and subsequently confirmed to be negative for parasite eggs by fecal zinc-sulphate base flotation technique, with no eggs detected. Additionally, all animals were tested for serum IgG specific antibodies for F. hepatica cathepsin L1 (FhCL1) by ELISA, obtaining negative results in all cases. During the experience, animals were housed indoors in the experimental farm of the University of Cordoba and fed with hay and commercial pellet.

Sheep were randomly distributed in four groups called vaccine 1 (VAC1), vaccine 2 (VAC2), infected controls (IC) and uninfected controls (UC). Groups VAC1 $(n=10)$ and VAC2 $(n=10)$ were immunized subcutaneously with two doses, 4 weeks apart, of a multivalent vaccine. The formulation of the two vaccines assessed in this study were published previously by [11] finding a reduction of fluke burden (37.2\%) and egg output $(28.71 \%)$ in comparison to IC group. Briefly, each vaccine dose $(2 \mathrm{~mL})$ contained a cocktail of F. hepatica recombinant proteins including cathepsin L1 (rFhCL1), peroxiredoxin (rFhPrx), helminth defence molecules (rFhHDM), and leucine aminopeptidase (rFhLAP) at a concentration of $100 \mu \mathrm{g}$ per antigen emulsified in two different adjuvants, Montanide ISA 61 VG (Seppic, Puteaux, France) and Alhydrogel ${ }^{\circledR}$ adjuvant $2 \%$ (InvivoGen, San Diego, CA, USA), respectively. The F. hepatica recombinant proteins were obtained as described [11]. Group IC $(n=10)$ was unimmunized and infected; and group UC $(n=7)$ was unimmunized and uninfected. Eight weeks after the first immunization, groups VAC1, VAC2, and IC were infected orally with 150 metarcercariae of the South Gloucester strain of F. hepatica (Ridgeway Research Ltd., UK) administered in gelatin capsules with a dosing gun. At 15 weeks post-infection (wpi), all animals were culled in batches of six per day by intravenous injection of a proper dose of T61 ${ }^{\circledR}$ (MSD Animal Health, Salamanca, Spain) according to manufacturer's instruction. The experiment was approved by the Bioethics Committee of the University of Cordoba (No. 1118, date 11 January 2016) and was performed considering European (2010/63/UE) and Spanish (L32/2007 and RD53/2013) directives on animal experimentation. Fluke burden and gross pathology of the liver were reported by [11].

\subsection{Liver Pathology}

During necropsy, livers were removed and a total of six hepatic samples per liver were collected from hepatic lesions from both the right and left hepatic lobes of each animal. In the UC group, liver samples were randomly collected from the left and right hepatic lobes. Next, all the samples were fixed in $10 \%$ buffered formalin for $24 \mathrm{~h}$ and routinely processed and embedded in paraffin wax. Tissue sections ( $4 \mu \mathrm{m}$ thick) were stained with hematoxylin and eosin (H\&E) and evaluated independently by two pathologists to assess the severity of the hepatic lesions per animal and group, as follows: 0 , absent; 1 , mild; 2, moderate; 3 , severe; 4, very severe. The parameters scored were related to chronic stages of the infection and immunized groups (VAC1 and VAC2) were compared to the unimmunized and infected group (IC). The pathological changes studied were fibrous perihepatitis, chronic migratory tracts, bile duct hyperplasia, periportal fibrosis, granulomas, eosinophilic and lymphoplasmacytic infiltrates, globule leukocytes and parasite eggs within the bile ducts or in the hepatic parenchyma.

\subsection{Immunohistochemistry}

The avidin-biotin-peroxidase (ABC) method was used on paraffin wax liver sections of 3- $\mu \mathrm{m}$ thick as previously described [12]. Briefly, tissue sections were dewaxed, rehydrated and endogenous peroxidase activity was exhausted by incubation with $0.3 \%$ hydrogen peroxide in methanol for $30 \mathrm{~min}$ at room temperature (RT). Tissue sections were incubated in different retrieval antigen pre-treatments based on the primary antibody used (Table 1). 
After three rinses in phosphate-buffered saline (PBS, pH 7.2), tissue sections were incubated with $20 \%$ normal goat serum (MP Biomedicals) for $30 \mathrm{~min}$ at RT. Endogenous liver biotin was blocked using the Avidin/Biotin blocking kit (Vector Laboratories) following the manufacturer instructions. A panel of primary antibodies were diluted in PBS containing $10 \%$ normal goat serum (Table 1) and incubated overnight at $4{ }^{\circ} \mathrm{C}$. Following washing in PBS, biotinylated goat anti-rabbit or anti-mouse secondary antibodies (Dako, Agilent, E0432 and E0433, respectively) diluted 1:200 and 1:50, respectively, were applied correspondingly for $30 \mathrm{~min}$ at RT. After washing in PBS, the sections were incubated with the ABC complex (Vectastain ABC Elite Kit) for $1 \mathrm{~h}$ at RT in darkness, washed in $0.05 \mathrm{M}$ Tris buffered saline ( $\mathrm{pH}$ 7.6), and then incubated in the chromogen solution (Vector NovaRED Peroxidase Substrate Kit). Finally, the sections were counterstained with Harris' hematoxylin and mounted in Eukitt quick-hardening mounting medium. Tissue sections in which the specific primary antibodies were replaced by non-immune isotype antibody were used as negative controls.

Table 1. Specificity of primary antibodies for immunohistochemical study.

\begin{tabular}{|c|c|c|c|}
\hline Antibody ${ }^{1}$, Clon or Ref, Source & Expression & Dilution & Retrieval Method \\
\hline CD163 mAb, EdHu-1, BioRad & Mac. (M2) & $1: 400$ & TC pH6 Autocl. ${ }^{2}$ \\
\hline Lysozyme pAb, A0099, Dako & Mac. & $1: 200$ & TC $\mathrm{pH}_{6} \mathrm{MW}^{3}$ \\
\hline S100 pAb, Z0311, Dako & Mac., DC & $1: 200$ & None \\
\hline CD68 mAb, EBM11, Dako & Mac. & $1: 50$ & Pronase $^{4}$ \\
\hline CD3 pAb, A0452, Dako & Pan T lymp. & $1: 200$ & TC pH6 MW 3 \\
\hline $\begin{array}{c}\text { Lambda light chains pAb, } \\
\text { A0193, Dako }\end{array}$ & B cells & 1:1000 & Pronase 4 \\
\hline FoxP3 mAb, FJK-16s, eBiosciences & $\mathrm{T}$ reg & $1: 100$ & TC pH6 Autocl. ${ }^{5}$ \\
\hline HLA-DR mAb, TAL.1B5, Dako & MHC-II APC & $1: 50$ & TC $\mathrm{pH}_{6} \mathrm{MW}^{3}$ \\
\hline $\begin{array}{c}\text { CD208 (DC-LAMP) mAb, } \\
\text { 1010E1.01, Dendritics }\end{array}$ & Mature DC & $1: 100$ & TC pH6 Autocl. ${ }^{2}$ \\
\hline Ki67 mAb, MIB-1, Dako & Proliferating cells & 1:100 & TC pH6 Autocl. ${ }^{2}$ \\
\hline Cytokeratin mAb, AE1/AE3, Dako & Epithelial cells & $1: 50$ & TC pH6 Autocl. ${ }^{2}$ \\
\hline
\end{tabular}

${ }^{1}$ Monoclonal antibody $(\mathrm{mAb})$ or polyclonal antibody (pAb). ${ }^{2}$ Incubation with $0.1 \mathrm{M}$ citric acid (pH 6), autoclave at $121{ }^{\circ} \mathrm{C}$ for $20 \mathrm{~min} .{ }^{3}$ Incubation with $0.1 \mathrm{M}$ citric acid (pH 6), microwave for $10 \mathrm{~min}$ at sub-boiling temperature. ${ }^{4}$ Incubation with $0.1 \%$ protease type XIV (Sigma-Aldrich) in $0.01 \mathrm{M} \mathrm{PBS,} \mathrm{pH} 7.2$ for 5 min at RT. ${ }^{5}$ Incubation with $0.1 \mathrm{M}$ citric acid ( $\mathrm{pH}$ 6), autoclave at $135^{\circ} \mathrm{C}$ for $10 \mathrm{~min}$. Mac.: macrophages; DC: dendritic cells; lymp.: lymphocytes; Treg: regulatory T cells; APC: antigen presenting cells.

\subsection{Cell Counting}

Immunostained cells with the different antibodies used in the study were counted in five areas of $0.08 \mu \mathrm{m}^{2}$, randomly selected areas in granulomatous lesions associated to degenerated flukes. Results were expressed as mild: $<10$ immunostained cells per field; moderate: 10-30 immunostained cells per field; severe: 30-50 immunostained cells per field; and very severe: $>50$ immunostained cells per field.

\subsection{Statistical Analysis}

Statistical analysis was carried out for the histopathological hepatic lesions using the Graphpad Prism 7.0 software package (Graphpad Software, Inc., San Diego, CA, USA). A non-parametrical one-way ANOVA Kruskal-Wallis test with Dunn's post-hoc test was carried out. $p$ values $<0.01$ were considered very statistically significant and $p$ values $<0.05$ were considered statistically significant.

\section{Results}

\subsection{Histopathological Evaluation of Hepatic Lesions}

The livers of the UC group showed no histopathological changes, portal areas showed scarce connective tissue with occasional lymphocytes. The scores of the microscopical hepatic lesions of the three infected groups (VAC1, VAC2, and IC) are summarized in Figure 1. 


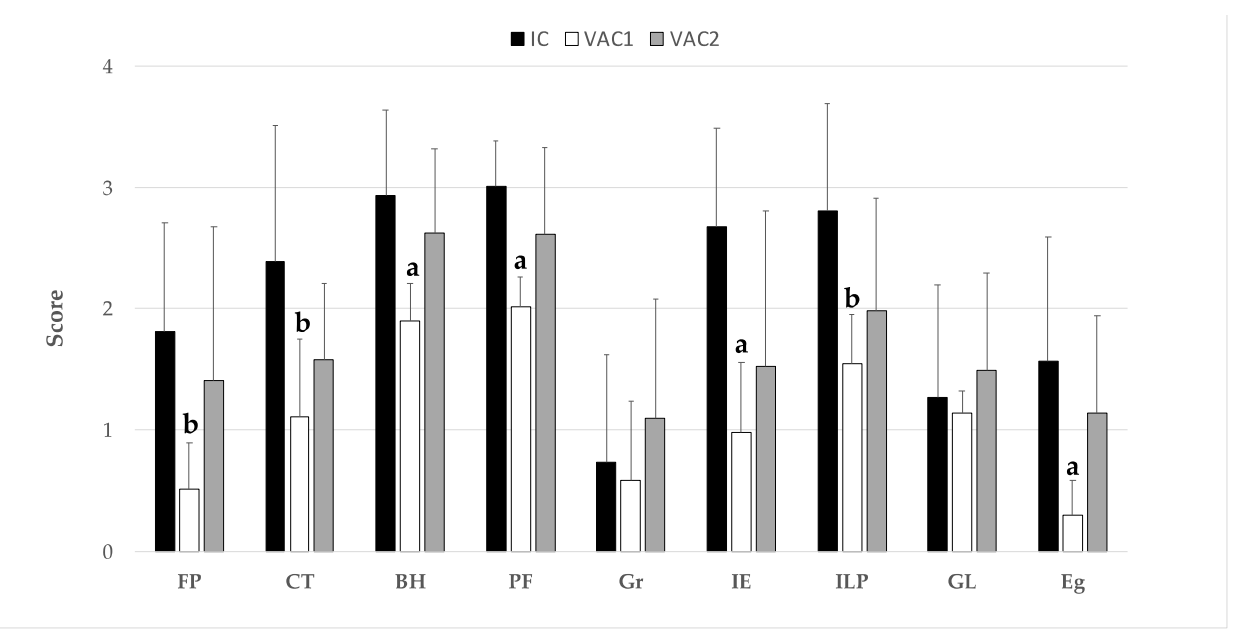

Figure 1. Evaluation of histopathological findings after Fasciola hepatica infections from immunized (VAC1 and VAC2) and unimmunized sheep (IC). Bars and error bars represent mean $(n=10)$ and $\mathrm{SD}$, respectively. Score represents the severity of the lesions as: 0 , absent; 1 , mild; 2 , moderate; 3 , severe; 4 , very severe. ${ }^{\mathbf{a}, \mathbf{b}}$ Statistical difference $(p<0.01$ and $p<0.05$, respectively) compared to the IC group. FP: fibrous perihepatitis; CT: chronic tracts; $\mathrm{BH}$ : bile duct hyperplasia; PF: portal fibrosis; Gr: granulomas; IE: inflammatory infiltrate of eosinophils; ILP: inflammatory infiltrate of lymphocytes and plasma cells; GL: globule leukocytes; Eg: F. hepatica eggs.

Fibrous perihepatitis consists of focal fibrosis with or without infiltrate of lymphocytes and plasma cells in the Glisson's capsule coinciding with the healing of the lesions induced by migrating larvae when they penetrate in the liver or the healing of superficial migratory tracts (Figure $2 \mathrm{a}, \mathrm{c}, \mathrm{e})$. The severity of this lesion was significantly lower $(p<0.05)$ in the VAC1 group compared with the IC group, while in theVAC2 group it was slightly lower than in the IC group but without significant differences (Figure 1). Chronic tracts are composed of fibrosis and macrophages loaded with hemosiderin pigment (Figure $2 \mathrm{~b}, \mathrm{~d}, \mathrm{f}$ ) as a consequence of the healing migratory tunnels with hemorrhages induced by migrating larvae. The VAC1 group presented significantly lower chronic tracts $(p<0.05)$ than the IC group whereas VAC2 groups showed slightly lower severity of chronic tracts than IC group but with no significant differences (Figure 1).

Bile duct hyperplasia consists of enlargement of bile ducts and presence of papilla to increase the surface of epithelium (Figure $3 a, c, e$ ) and it is due to the presence of adult F. hepatica in the lumen of bile duct causing mechanical irritation with the spines and oral sucker and chemical irritation due to the excretory secretory (ES) product that the adult parasite release. The VAC1 group showed significantly $(p<0.01)$ lower severity bile duct hyperplasia than the IC group (Figure 1) while no significant differences were found between VAC2 and IC groups. Portal fibrosis is another common hepatic lesion of chronic fasciolosis and consist of fibrosis in the portal spaces, particularly in those showing bile duct hyperplasia (Figure 3a,c,e). The VAC1 group showed significantly $(p<0.01)$ lower portal fibrosis than the IC group (Figure 1) but no significant differences were recorded for portal fibrosis between the VAC2 and IC groups (Figure 1). 


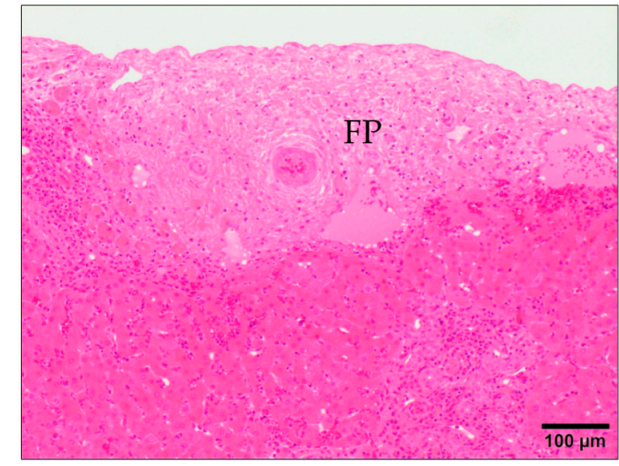

(a)

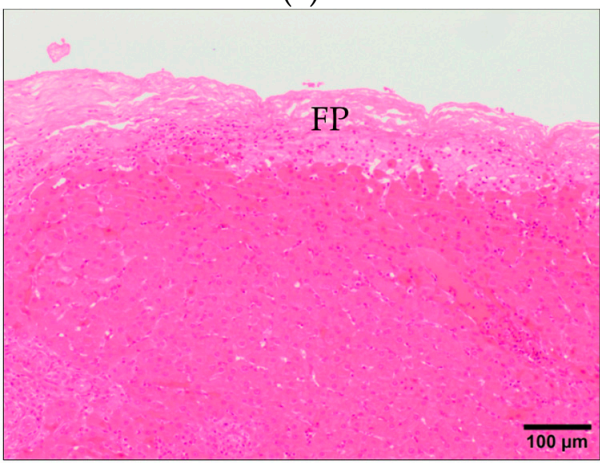

(c)

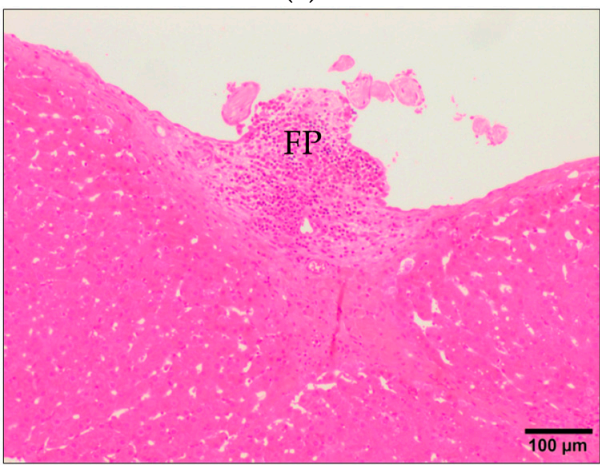

(e)

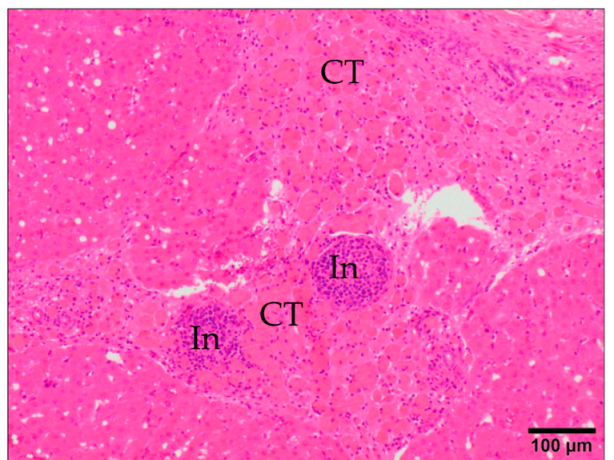

(b)

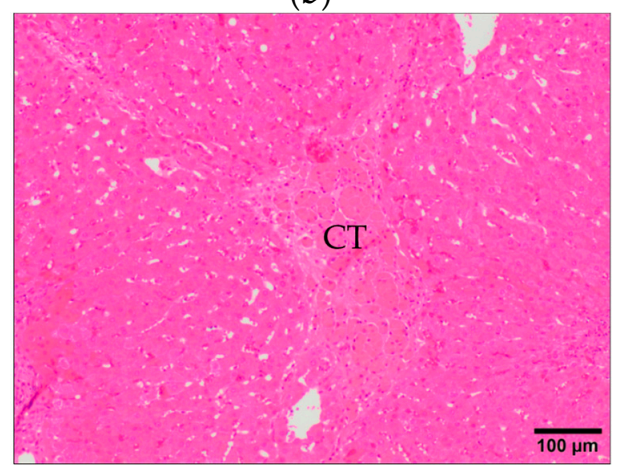

(d)

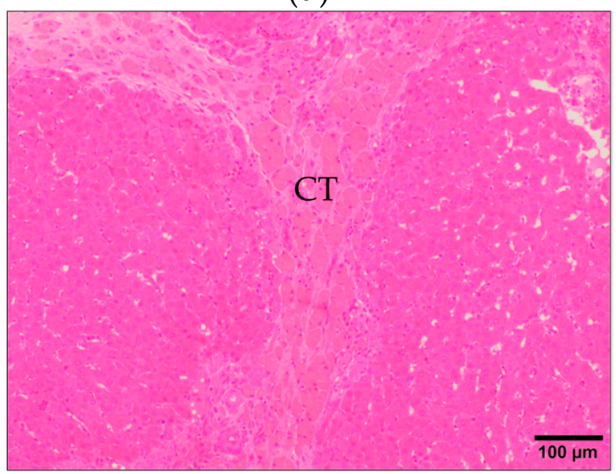

(f)

Figure 2. Main histopathological findings related to fasciolosis. (a,c,e) Fibrous perihepatitis (FP) in the Glisson's capsule with focal fibrosis and inflammatory infiltrate from IC, VAC1, and VAC2 groups, respectively; $(\mathbf{b}, \mathbf{d}, \mathbf{f})$ chronic tracts $(\mathrm{CT})$ displaying fibrosis and macrophages loaded with hemosiderin pigment from IC, VAC1, and VAC2 groups, respectively. In: inflammatory infiltrates. H\&E stain.

Granulomas composed of a necrotic center surrounded by a core of epithelioid macrophages and in some cases multinucleate giant cells and outer inflammatory infiltrate of eosinophils and lymphocytes (Figure $3 b, d, f$ ) were found in the two vaccinated groups and in the IC group, but the individual variability of this lesion was high in the three groups and there were no significant differences between vaccinated groups and the IC group (Figure 1). Inflammatory infiltrate of eosinophils was common in portal areas (Figure $4 \mathrm{a}, \mathrm{c}, \mathrm{e}$ ), in the periphery of granulomas and surrounding parasite eggs that reached the hepatic parenchyma. The group VAC1 showed a significantly $(p<0.01)$ less severe infiltration of eosinophils than group IC, whereas the group VAC2 presented highly individual variability and a slightly lower infiltration than group IC but without significant differences (Figure 1). Inflammatory infiltrate of lymphocytes and plasma cells was also common in portal areas (Figure $4 \mathrm{a}, \mathrm{c}, \mathrm{e}$ ) and in the periphery of granulomas, in some cases this infiltrate 
was arranged forming lymphoid follicles. The group VAC1 showed a less severe $(p<0.05)$ infiltration of lymphocytes and plasma cells than group IC, among the group VAC2 and IC no significant differences were recorded although the infiltration of eosinophils tends to be more pronounced in the group IC (Figure 1). Globule leukocytes with wide cytoplasm containing large eosinophilic granules were observed in the epithelium of some bile ducts, particularly in hyperplastic ducts. The score for globule leukocytes was similar in the three infected groups without significant differences between them (Figure 1). F. hepatica eggs were observed within some bile ducts (Figure $4 \mathrm{~b}, \mathrm{~d}, \mathrm{f}$ ) and in some cases in the hepatic parenchyma associated to a severe inflammatory response with abundant eosinophils. The score for presence of parasite eggs was higher in the IC group than in VAC1 group, without significant differences between the IC and VAC2 groups (Figure 1).

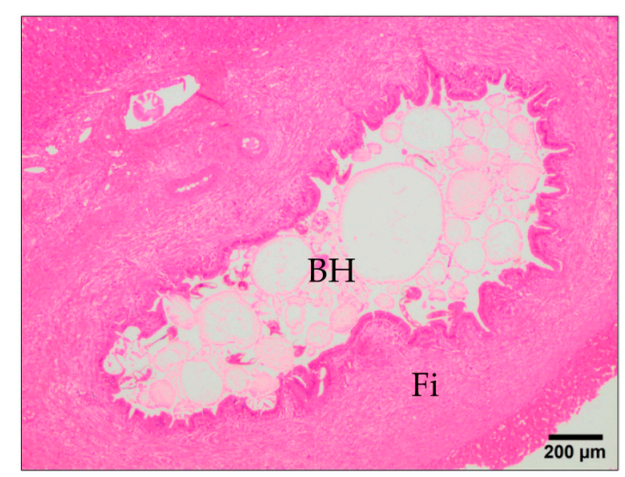

(a)

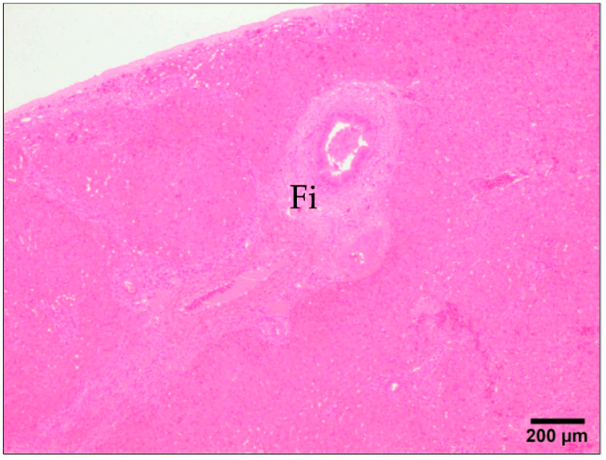

(c)

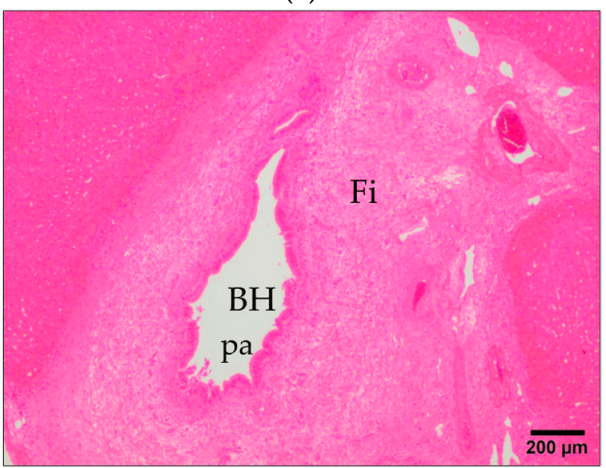

(e)

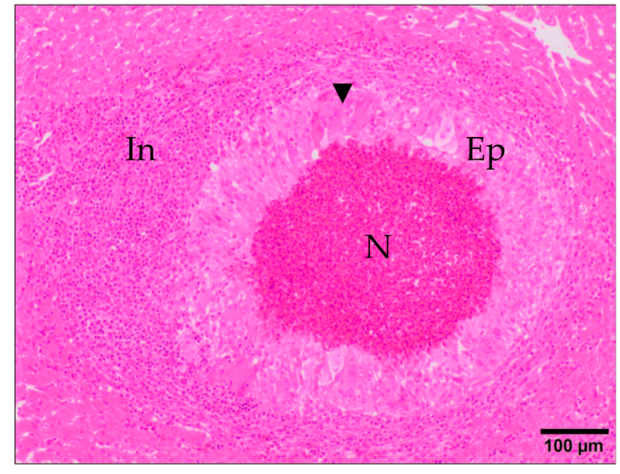

(b)

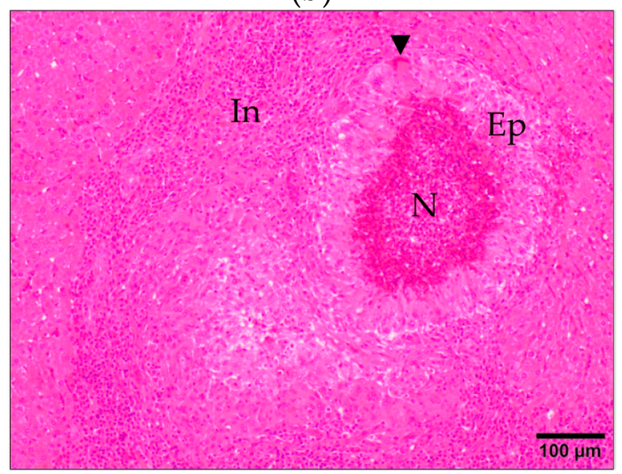

(d)

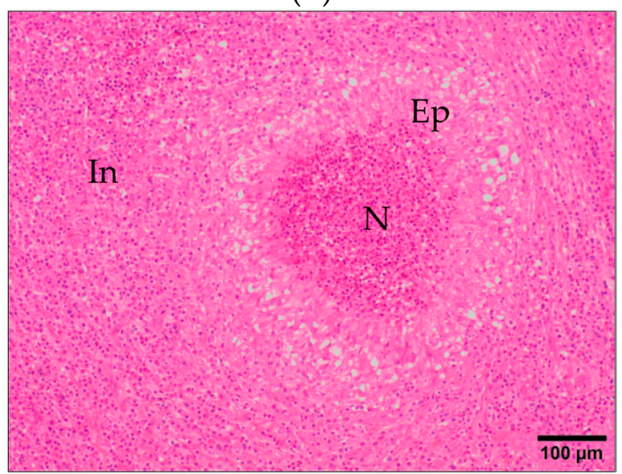

(f)

Figure 3. Main histopathological findings related to fasciolosis. (a,c,e) Portal fibrosis showing a thick fibrosis band (Fi) surrounding a hyperplasic bile duct $(\mathrm{BH})$ consisting of enlargement of bile ducts and presence of papilla (pa) to increase the surface of epithelium from IC, VAC1, and VAC2 groups, respectively. (b,d,f) Granuloma with a necrotic center $(\mathrm{N})$ surrounded by a core of epithelioid macrophages (Ep) and in some cases multinucleate giant cells (arrowhead) and outer inflammatory infiltrates (In) from IC, VAC1, and VAC2 groups, respectively. H\&E stain. 


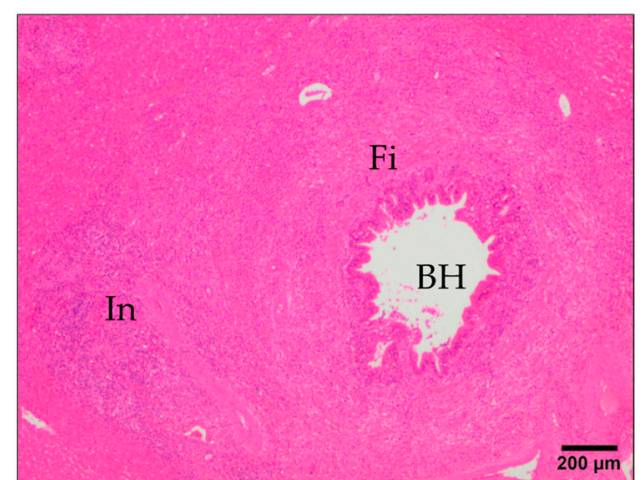

(a)

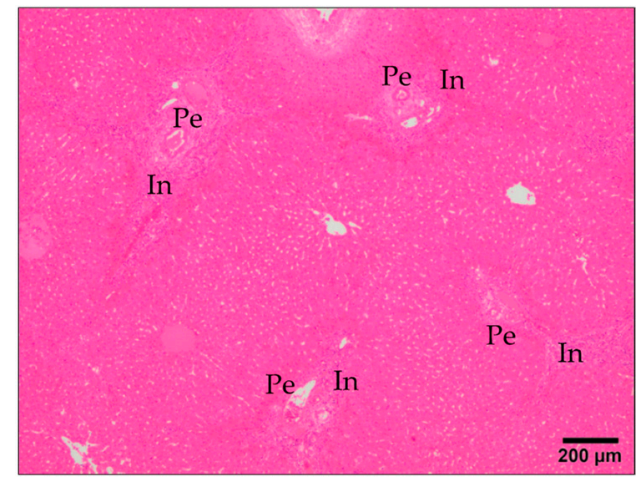

(c)

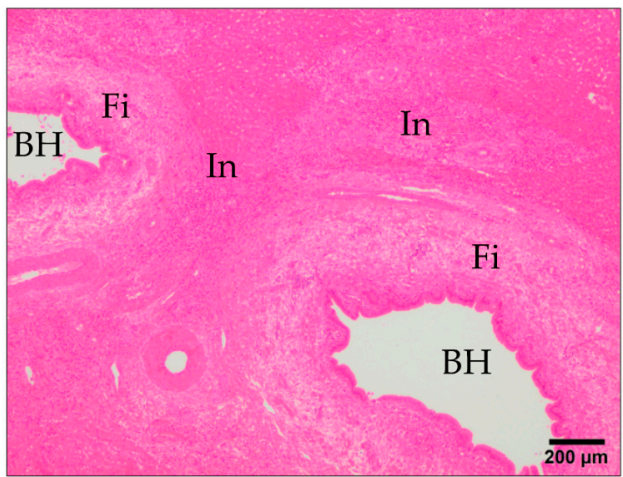

(e)

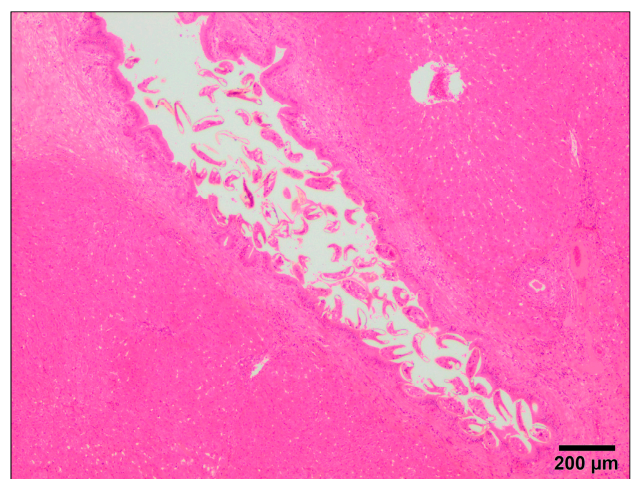

(b)

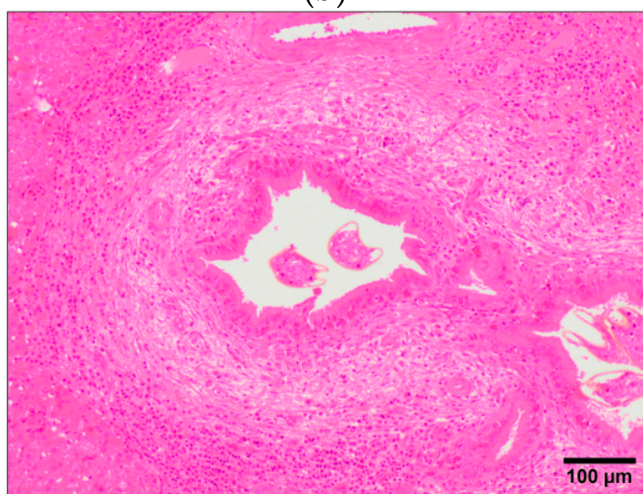

(d)

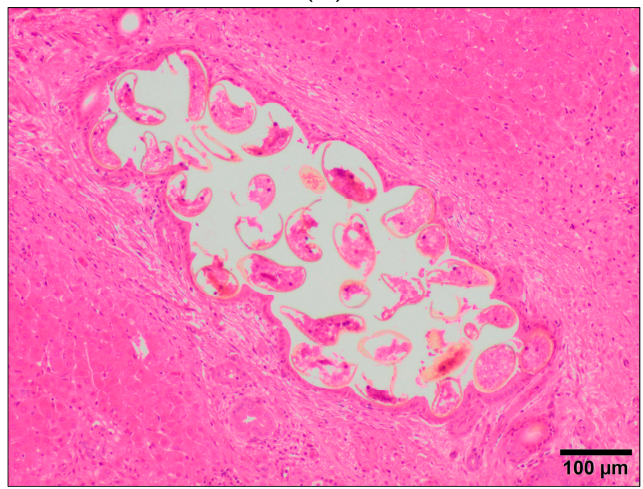

(f)

Figure 4. Main histopathological findings related to fasciolosis. (a,c,e) Inflammatory infiltrates (In) of eosinophils and/or lymphocytes and plasma cells from IC, VAC1, and VAC2 groups, respectively; $(\mathbf{b}, \mathbf{d}, \mathbf{f})$ Eggs contained within bile ducts from IC, VAC1, and VAC2 groups, respectively. BH: bile duct hyperplasic; Fi: fibrosis band; Pe: periportal space. H\&E stain.

\subsection{Evaluation of F. Hepatica Morphology}

During chronic fasciolosis the parasites are allocated within the bile ducts as adults and as consequence of their hermaphrodite reproductive strategy they are able to shed thousands of eggs per day. In this study conducted at 15 wpi, F. hepatica adults were allocated within the hyperplasic bile ducts surrounded by a thick fibrous capsule (Figure 5a). The anatomy of these adults showed the gastrointestinal and reproductive tracts intact with the normal morphology (Figure 5b,c) as has been described previously [13,14]. Moreover, the tegument presented well-developed eosinophilic spines (Figure 5b) which cause mechanical damage of the bile duct epithelium. These adults were reproductively viable confirmed by the high number of eggs found within the reproductive tract of the parasites observed and the eggs found within the lumen of the bile ducts (Figure 5c). Apparently, these eggs 
were viable containing cells which correspond to the fertilized ovum and vitelline cells enclosed in a yellowish capsule.

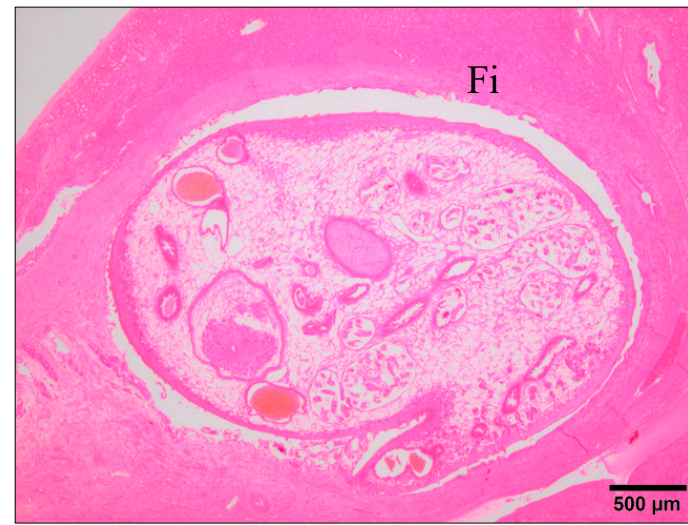

(a)

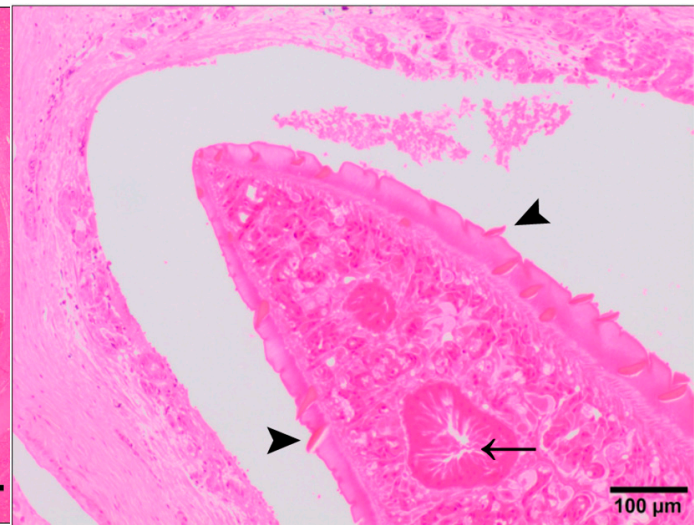

(b)

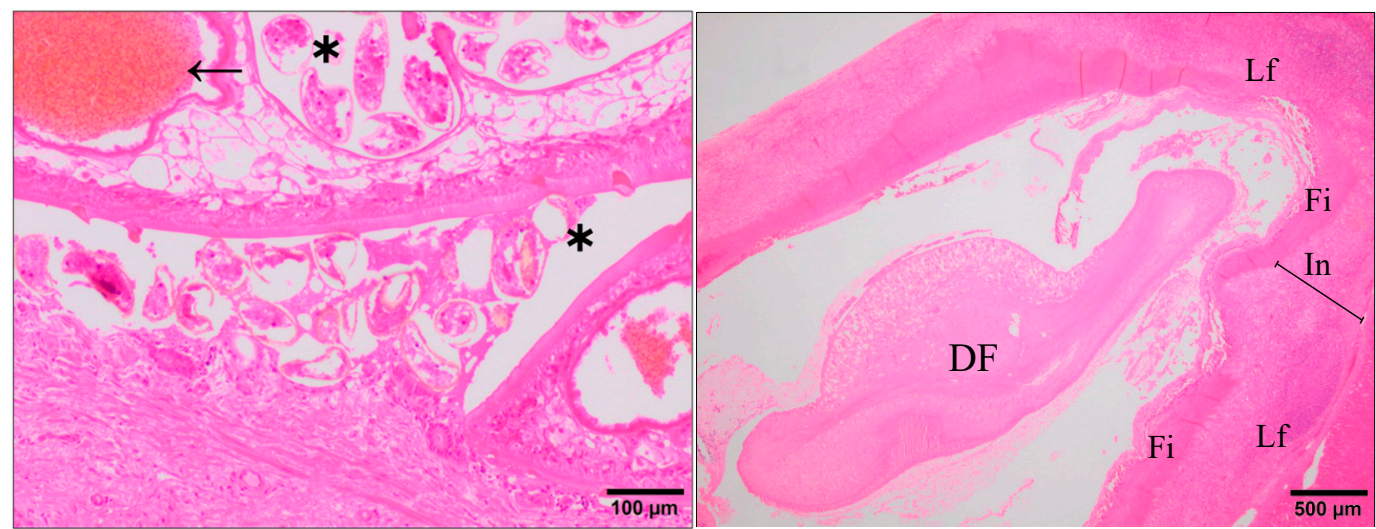

(c)

(d)

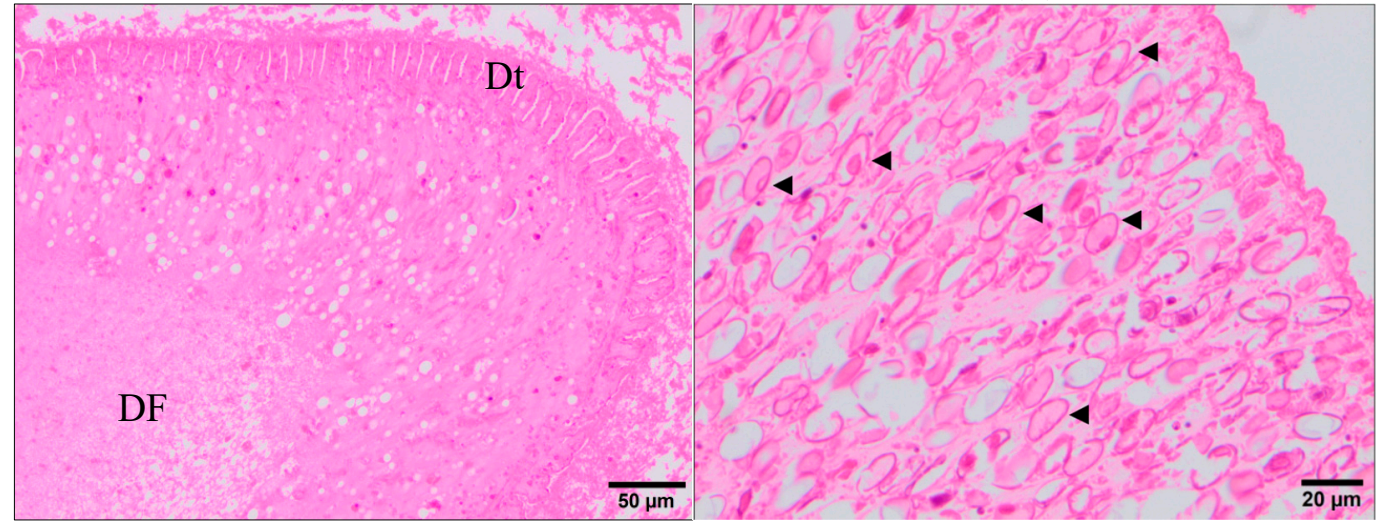

(e)

(f)

Figure 5. Anatomical morphology of Fasciola hepatica. (a-c) IC group; (d-f) VAC1 group. Fi: fibrous tissue; Lf: lymphoid follicles; Arrowhead: tegument spines of a normal Fasciola hepatica; Arrow: gastrointestinal tract of a normal Fasciola hepatica; *: viable reproductive tract with eggs of a normal Fasciola hepatica; DF: degenerated adult of Fasciola hepatica; In: inflammatory infiltrate; Dt: degenerated tegument; Arrowhead: F. hepatica eggs. H\&E stain.

Unexpectedly, four sheep from the VAC1 group showed occasional degenerated forms of $F$. hepatica (Figure $5 \mathrm{~d}-\mathrm{f}$ ) within bile ducts that were surrounded by a thick band of fibrous tissue and by an unusual severe outermost granulomatous inflammatory infiltrate with the presence of lymphoid follicles (Figure 5d). The majority of epithelium of bile ducts containing degenerated flukes was desquamated but it was possible to identify some 
epithelial bile duct cells using the cytokeratin AE1 / AE3 antibody as marker for this cell type (Figure 6d). Occasionally, necrotic tissue was found surrounding degenerated parasites. Compared with the viable parasites, degenerated flukes showed a marked homogeneous eosinophilia lacking cell nuclei. Moreover, the tegument displayed a loss of spines and its morphology changes drastically toward a waving structure shedding acidophilic tissue associated and the reproductive and digestive systems could not be identified (Figure 5e). Additionally, it was also possible to observe degenerated eggs which could be identified in some cases according to their morphological features and the sclerotin-based eggshell (Figure 5f). These degenerated flukes were considered dead flukes and the bile ducts containing them were associated to a severe granulomatous reaction characterized by a layer of large epithelioid macrophages and multinucleate giant cells surrounding the dead flukes and necrotic tissue, a middle layer mainly composed of lymphocytes with lymphoid follicle formation, some of them showing large germinal center, and an outer layer of fibrous connective tissue.

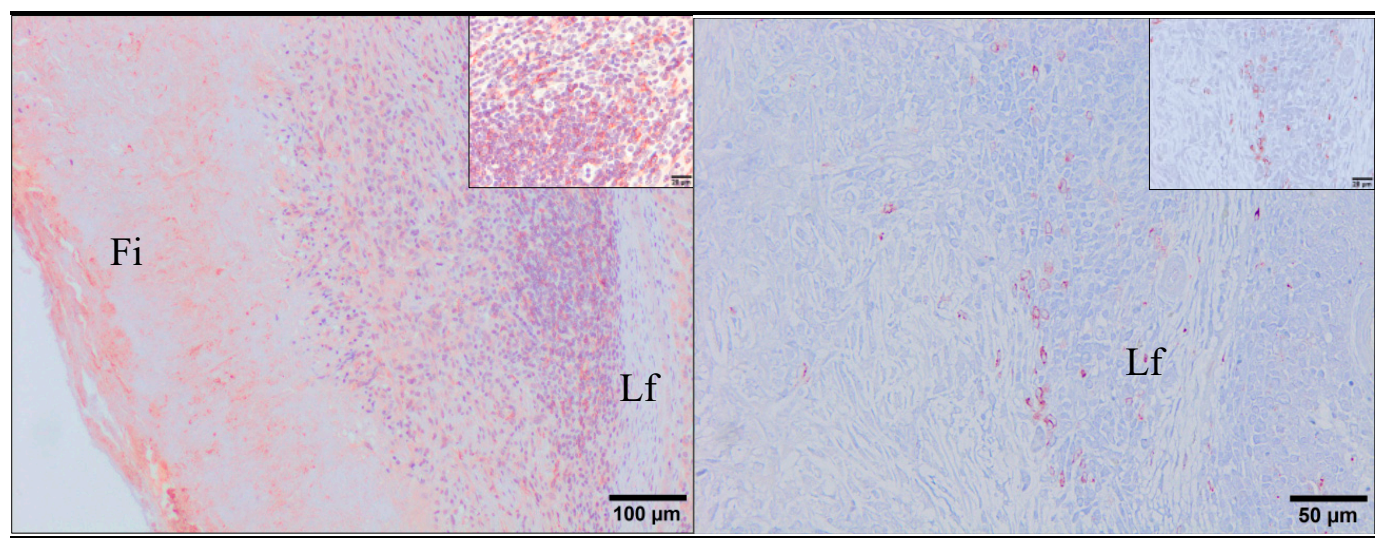

(a)

(b)

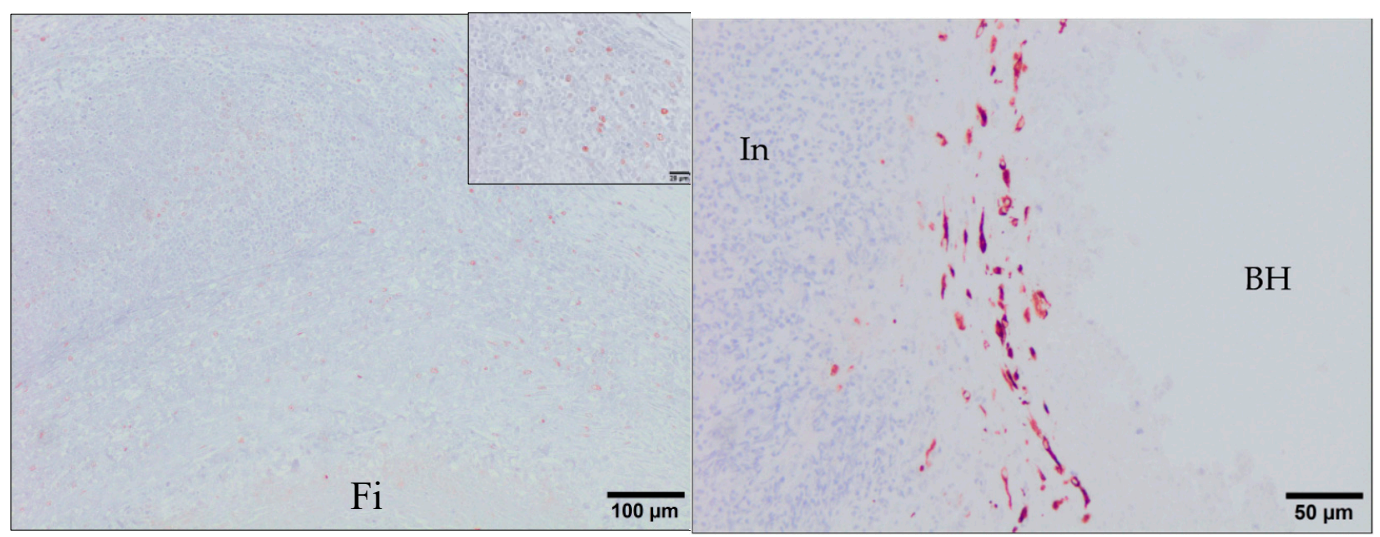

(c)

(d)

Figure 6. Immunohistochemical characterization of the inflammatory infiltrates surrounding the degenerated adults of $F$. hepatica in immunized sheep with a multivalent vaccine and Montanide 61 VG as adjuvant. The markers used were: (a) MHCII+ antigen presenting cells; (b) CD208+ mature dendritic cells; (c) Ki67+ proliferating cells; (d) AE3/AE1+ epithelial cells from a hyperplasic bile duct. Fi: fibrous tissue; Lf: lymphoid follicles; BH: hyperplasic bile duct; In: inflammatory infiltrate. Inner magnification showing the stain pattern. Positive immunostaining cells are shown in brown-red. ABC method.

The inflammatory infiltrates associated to degenerated flukes from the group VAC1 were characterized by immunohistochemistry using primary antibodies described in Table 1 and scored in base of the number of positive immunostained cells (Table 2). The immunohistochemical study revealed that the inflammatory infiltrates surrounding degenerated flukes from in the VAC1 group contained a high number of macrophages alterna- 
tively activated-M2 (CD163+) (Figure 7a), as well as a high number of macrophages and multinucleate giant cells strongly labelling by the lysozyme and S100 antibodies (Figure $7 \mathrm{~b}, \mathrm{c}$, respectively). The CD68 antibody was expressed weakly by epithelioid macrophages and multinucleate giant cells in the inner layer of granulomas while it was expressed strongly by circulating monocytes, Kupffer cells, and macrophages located at the periphery of granulomas and in portal spaces. CD163+ cells were also present in the outermost inflammatory infiltrate of granulomas but they were not found within the lymphoid follicles. The CD163 stain is strictly membranous displaying a strong intensity. Thus, the morphology of the CD163+ stained cells are compatible with macrophages. However, lysozyme and S100 antibodies performed a strong cytoplasmic stain that immunolabeled the epithelioid macrophages highlighting the presence of multinucleated giant cells. They were also located in the middle area between the fibrous tissue and the outermost inflammatory infiltrate with no positivity within the lymphoid follicles.

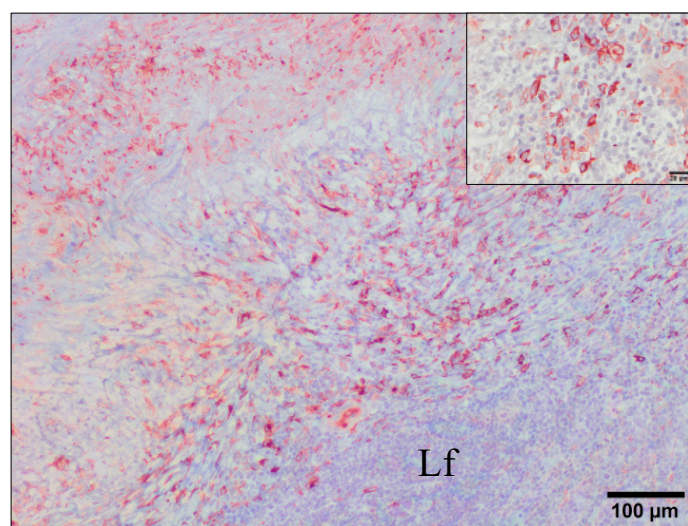

(a)

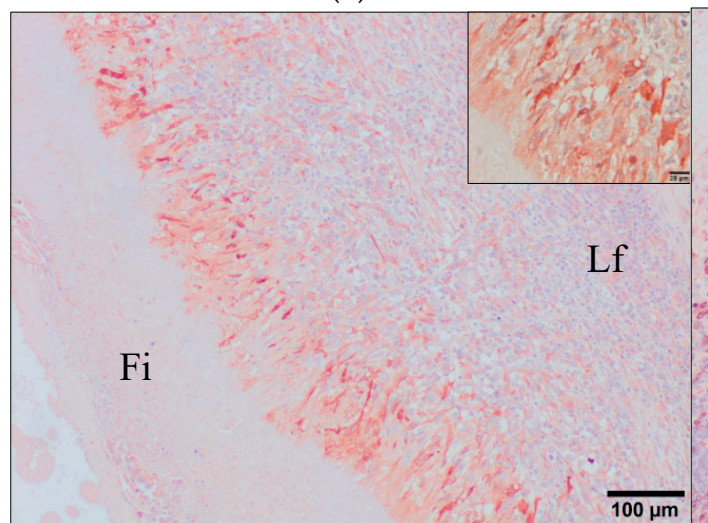

(c)

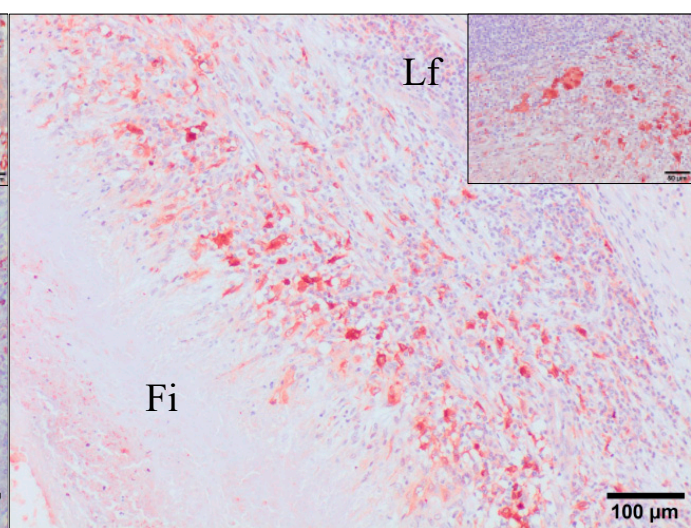

(b)

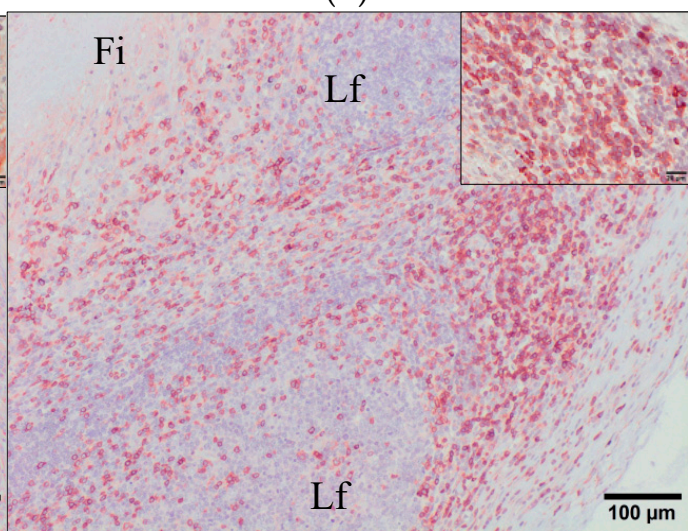

(d)

Figure 7. Cont. 


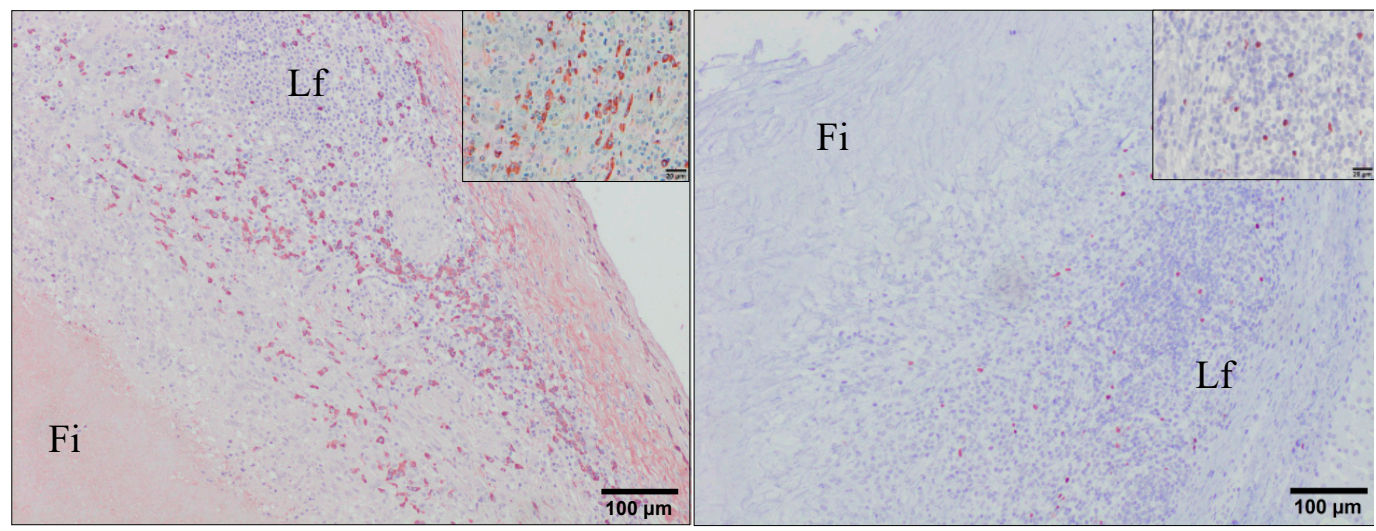

(e)

(f)

Figure 7. Immunohistochemical characterization of the inflammatory infiltrates surrounding the degenerated adults of F. hepatica in immunized sheep with a multivalent vaccine and Montanide $61 \mathrm{VG}$ as adjuvant. Immunohistochemistry was carried out by using several markers for macrophages: (a) CD163; (b) lysozyme (inner magnification showing immunolabelled giant cells); (c) S100; and for lymphocytes: (d) CD3; (e) lambda light chains-B cells; (f) FoxP3-Treg. Fi: fibrous tissue; Lf: lymphoid follicles. Inner magnification showing the stain pattern. Positive immunostaining cells are shown in brown-red. ABC method.

Table 2. Evaluation of the immunostaining cells in the granulomatous lesions associated to dead flukes of Fasciola hepatica.

\begin{tabular}{ccc}
\hline Antibody & Cellular Expression & Score $^{\mathbf{1}}$ \\
\hline CD163 & Mac. (M2) & Severe \\
Lysozyme & Mac. & Severe \\
S100 & Mac., DC & Severe \\
CD68 & Mac. & Mild \\
CD3 & Pan T lymp. & Very severe \\
Lambda light chains & B cells & Moderate \\
FoxP3 & T reg & Mild \\
HLA-DR & MHC-II APC & Moderate \\
CD208 (DC-LAMP) & Mature DC & Mild \\
Ki6 & Proliferating cells & Mild \\
Cytokeratin (AE1/AE3) & Epithelial cells & Mild \\
\hline
\end{tabular}

${ }^{1}$ Mild: <10 immunostained cells per field; moderate: 10-30 immunostained cells per field; severe: $30-50$ immunostained cells per field; and very severe: $>50$ immunostained cells per field. Mac.: macrophages; DC: dendritic cells; lymp.: lymphocytes; Treg: regulatory T cells; APC: antigen presenting cells.

The outer inflammatory infiltrate was composed by abundant lymphocytes, the majority of them reacted with the CD3 antibody (Figure 7d), whereas the presence of B cells ( $\operatorname{IgG}$ lambda light chain+) was moderate (Figure 6e) and the FoxP3+-expressing regulatory $\mathrm{T}$ cells was scarce (Figure 7f). The cells CD3+ and B cells were localized in larger quantities in the inflammatory infiltrates outside the lymphoid follicles being present to a lesser extent within them. The staining pattern of both CD3 and IgG-lambda light chain antibodies was cytoplasmic with membranous strong intensity showing a morphology fully compatible with lymphocytes. The Foxp3+ cells showed nuclear and cytoplasmic staining pattern with a strong intensity, being localized dispersed within the outermost inflammatory infiltrate. Moreover, these infiltrates presented a high number of antigen presenting cells positive to MHC-II (HLA-DR+) marker (Figure 6a) displaying a cytoplasmic stain with moderate intensity and morphologically compatible with lymphocyte and macrophages. This positivity was present mainly within the lymphoid follicles but also dispersed along the inflammatory infiltrate area. However, the number of mature dendritic cells (CD208+) (Figure 6b) and proliferating cells (Ki-67+) (Figure 6c) was very scarce. The CD208 positivity was membranous with moderate intensity immunolabelling a very low number 
of cells in the outermost inflammatory infiltrate localized mainly in the surroundings of the lymphoid follicles. The Ki-67 marker was intranuclear with a strong intensity being localized randomly dispersed within the outermost inflammatory infiltrate.

\section{Discussion}

The VAC1 included in the present study was considered partially protective since it induced a fluke burden reduction of $37.2 \%(p=0.002)$ and a significant reduction $(p=0.03)$ of gross hepatic lesion compared to the IC group. However, the VAC2 was considered non protective since it did not induce significant reduction of fluke burdens and gross hepatic lesions with respect to the IC group [11]. The results of the present study confirm the protective nature of VAC1 in term of histopathological hepatic lesions since it induced significant reduction of the majority of microscopical lesions scored (fibrous perihepatitis, chronic tracts, bile duct hyperplasia, portal fibrosis, inflammatory infiltrate of eosinophils, lymphocytes and plasma cells and presence of parasite eggs in bile ducts and hepatic parenchyma) in the VAC1 group with respect to the IC group. The only two lesions evaluated that showed no significant differences between the VAC1 group and the IC group were granulomas and infiltrate of globule leukocytes. On the other hand, the results of the present study also confirm that VAC2 was non protective since none of the microscopical hepatic lesions evaluated showed significant differences between the VAC2 and the IC groups. Among a variety of hematological, serological, and immunological parameters, the hepatic damage score is considered the best single index indicator of fluke burden, as has been previously reported in concern to F. gigantica by [15]. However, not much attention has been paid to evaluating hepatic damage as an additional indicator of protection in vaccine trials and only some studies have taken it into consideration [9,11,16-19].

Apart from the reduction of the above mentioned histopathological hepatic lesions, liver samples from the VAC1 group showed degenerated adults F. hepatica specimens within bile ducts, surrounded by a severe granulomatous inflammatory response. Degenerated flukes could be easily distinguished from viable flukes because they did not display the normal internal structures including reproductive and digestive tracts described previously [13,20-23] and, conversely, the internal body presented a homogenous acidophilic material that could be compatible with proteinaceous material after the denaturation of the proteins. Degenerated flukes have not been reported in previous pathological studies in experimental vaccine trials against $F$. hepatica $[11,16,17,19,24]$ or in experimental $F$. hepatica infections in sheep [25,26] and goats [27]. Furthermore, in rats the effective host response against $F$. hepatica is supposed to occur during early stages of infection at the intestinal lamina propria or peritoneal cavity while the lumen of the bile ducts where adult flukes are located is considered a relatively immunologically safe environment $[28,29]$. It has been reported that some migrating flukes may die during the migratory stage and become encapsulated in the hepatic parenchyma surrounded by a fibrous connective tissue capsule forming a cyst that may caseate and become mineralized [30]. In the present study degenerated flukes were found within enlarged bile ducts, moreover, some of them showed degenerated eggs which confirm they had reached maturity before they died. This is the first study reporting degeneration of adult flukes within bile ducts in a vaccine trial for F. hepatica. This finding may explain the lower reduction of fecal egg counts (FEC) than fluke burdens in the VAC1 group, since the degenerated flukes contained degenerated eggs, they could have been producing viable eggs during some weeks and became degenerated later.

The mechanism implicated in the occurrence of this aberrant morphology of the adult parasites after vaccination is certainly unknown, but they were only observed in the VAC1 group, which also showed a significantly fluke burden reduction with respect to the infected control group, while VAC2 in which degenerated flukes were not found, did not induce significant fluke burden reduction with respect to the IC group. It is possible that the host immune response generated by VAC1 may have induced an effect on the survival of adult flukes causing the degeneration of some of them, or the blockage of some of the 
four proteins used in vaccine formulation (FhCL1, FhLAP, FhHDM, and FhPrx) could have affected the viability of adult flukes in the VAC1 group. The adjuvant used in the vaccine formulation may also have influenced this effect since the only difference between the two vaccinated groups was the adjuvant. The presence of a very severe granulomatous reaction with the organization of lymphoid follicles surrounding the fibrous tissue close to the lumen of the bile ducts containing dead flukes was similar to that reported in granulomas associated to disintegration in porcine cysticercosis [31], human neurocysticercosis [32], and in other parasitic infections such as schistomiasis or leishmaniasis [33] and in granulomatous cholangitis associated to the trematode Campula spp. in cetaceans [34]. The presence of a well-formed granuloma-like entity surrounding the degenerated adult flukes has not been described before in vaccination studies in fasciolosis.

The characterization of the local cellular immune response induced by the vaccine and/or the parasite infection may provide key information regarding the type of cell subsets involved in it and consequently, help to better comprehend the mechanism triggered during the pathogenesis of $F$. hepatica infection. In this study, the immunological characterization of this inflammatory infiltrates revealed the presence of epithelioid macrophages and multinucleate giant cells strongly expressing both S100 and lysozyme antibodies forming an inner band surrounding degenerated flukes and necrotic tissue. Epithelioid cells are modified tissue macrophages composing certain granulomas associated with intense immunological activity and that can be induced by several infectious agents [35-37]. Lysozyme and S100 antibodies that are specific of phagocytes are claimed to immunolabel the epithelioid macrophages as well [38,39]. Moreover, there was a very high number of CD163+ macrophages which corresponds to M2-macrophages possessing mainly a homeostatic anti-inflammatory and tissue-repair function after a severe tissue injury, as occurs in human or cattle [40-44]. In the present study, M2-macrophages may have played a role in the formation of the abundant connective band of the middle band of the granulomas.

$\mathrm{CD} 3+\mathrm{T}$ lymphocytes constituted the major populations of the outer layer of the granulomas, this result is in agreement with the high number of this cell type in granulomas associated to remnants of the dead parasite Hypoderma lineatum but they were scarce in the periphery of viable larvae [45] and in the periphery of granulomatous cholangitis associated to the trematode Campula spp. in cetaceans [34]. This suggest that CD3+ T lymphocytes play a role in the local host response, either by producing cytokines to induce macrophage activation or tissue repair. B lymphocytes and plasma cells expressing IgG-lambda light chain were also abundant in the peripheral layer of the granulomas, suggesting a strong local humoral response, also reported in other parasitic granulomas [34,45].

The high number of HLA-DR+ cells located specifically within the lymphoid follicles which can be B cells, dendritic cells, and/or other antigen presenting cells, suggest that the role of these cell types is important in parasitic granulomas [33,46,47]. These HLA-DR+ cells are involved in the MHC class II-restricted antigen presentation that is essential for CD4+ $T$ cell-dependent immune responses suggesting an efficient adaptive immune response against F. hepatica in the $\mathrm{VAC1}$ group through an active presentation of antigens within the parasite-induced lymph follicles. Additionally, the low presence of CD208+ cells which is a marker expressed in human and ruminants by dendritic cells upon activation $[43,48,49]$ indicates a less relevant role of this cell population at this location.

The low number of Treg cells (FoxP3+) in the granulomas associated to dead flukes contrasts with the expansion of FoxP3+ cells in the liver of experimentally infected sheep and goats, particularly at the periphery of enlarged bile ducts [50,51]. The expansion of this cell type in helminth infections is considered an important immunomodulatory effect to facilitate parasite survival [52]. It is possible that VAC1 has had some effect blocking the expansion of Foxp 3 cells, which may have caused the local immune response to be more effective against flukes than in the IC and VAC2 groups. The low number of Ki-64+ cells in the granulomas indicates a low proliferation of cells at this late granuloma-like entity as has been reported by other authors in granulomatous lesions indicating the recruitment of cells mainly from blood instead of multiplying in situ [44]. 


\section{Conclusions}

The present study reports for the first time the presence of degenerated flukes associated to a severe granulomatous inflammation in bile ducts from sheep immunized with a partially protective vaccine (VAC1) composed of four recombinant proteins from F. hepatica in adjuvant Montanide 61 VG. The characterization of the granulomas associated to degenerated flukes revealed a high number of type 2 macrophages (CD163+) and CD3+ T lymphocytes with a low population of Foxp3+ Treg cells. Since sheep from the VAC1 group showed a significantly lower fluke burden and hepatic lesions than those from the infected control group, it is feasible that VAC1 may have induced certain effective host immune responses and at least, part of this response could have occurred against adult flukes allocated within the bile ducts.

Author Contributions: J.P., F.J.M.-M., and Á.M.-M. designed and supervised the experimental trial. V.M.-H., M.T.R.-C., L.B., R.Z., F.J.M.-M., M.J.B., A.E. and R.P.-C. performed the experiments. V.M.-H., M.T.R.-C., and J.P. analyzed the data. V.M.-H., M.T.R.-C., and J.P. wrote the original draft manuscript. L.B., R.Z., and Á.M.-M. review and editing the final manuscript. All authors have read and agreed to the published version of the manuscript.

Funding: This research was funded by the EU grant H2020-SFS-2014-2-635408-PARAGONE and MINECO grant PID2019-108782RB-C21. VMH was supported by the "Juan de la Cierva-Incorporacion" contract (IJCI-2017-31366) of the Spanish Ministry of Science, Innovation and Universities.

Institutional Review Board Statement: The study was conducted according to the guidelines of the Declaration of Helsinki, and approved by the Institutional Review Board (or Ethics Committee) of University of Cordoba (protocol code 1118 and date of approval 11 January 2016).

Informed Consent Statement: Not applicable.

Data Availability Statement: The data presented in this study are available on request from the corresponding author.

Acknowledgments: The authors are grateful to Carlos Carmona and Jose Tort (Universidad de la República, Montevideo, Uruguay) for supplying the recombinant protein rFhLAP, and John P. Dalton (School of Natural Sciences, National University of Ireland Galway, Galway, Ireland), for supplying the recombinant proteins $\mathrm{rFhCL} 1, \mathrm{rFhPrx}$ and $\mathrm{rFhHDM}$.

Conflicts of Interest: The authors declare no conflict of interest.

\section{References}

1. Charlier, J.; Rinaldi, L.; Musella, V.; Ploeger, H.W.; Chartier, C.; Vineer, H.R.; Hinney, B.; von Samson-Himmelstjerna, G.; Băcescu, B.; Mickiewicz, M.; et al. Initial assessment of the economic burden of major parasitic helminth infections to the ruminant livestock industry in Europe. Prev. Vet. Med. 2020, 182, 105103. [CrossRef] [PubMed]

2. Mas-Coma, S.; Valero, M.A.; Bargues, M.D. Facioliasis. Adv. Exp. Med. Biol. 2019, 1154, 71-103. [CrossRef] [PubMed]

3. Molina-Hernández, V.; Mulcahy, G.; Pérez, J.; Martínez-Moreno, Á.; Donnelly, S.; O’Neill, S.M.; Dalton, J.P.; Cwiklinski, K. Fasciola hepatica vaccine: We may not be there yet but we're on the right road. Vet. Parasitol. 2015, 208, 101-111. [CrossRef] [PubMed]

4. Beesley, N.J.; Caminade, C.; Charlier, J.; Flynn, R.J.; Hodgkinson, J.E.; Martinez-Moreno, A.; Martinez-Valladares, M.; Perez, J.; Rinaldi, L.; Williams, D.J.L. Fasciola and fasciolosis in ruminants in Europe: Identifying research needs. Transbound Emerg. Dis. 2018, 65, 199-216. [CrossRef] [PubMed]

5. Toet, H.; Piedrafita, D.M.; Spithill, T.W. Liver fluke vaccines in ruminants: Strategies, progress and future opportunities. Int. J. Parasitol. 2014, 44, 915-927. [CrossRef]

6. Meemon, K.; Sobhon, P. Development of Fasciola vaccine in an animal model. Methods Mol. Biol. 2016, 1404, 123-133. [CrossRef]

7. Buffoni, L.; Garza-Cuartero, L.; Pérez-Caballero, R.; Zafra, R.; Martínez-Moreno, F.J; Molina-Hernández, V.; Pérez, J.; MartínezMoreno, Á.; Mulcahy, G. Identification of protective peptides of Fasciola hepatica-derived cathepsin L1 (FhCL1) in vaccinated sheep by a linear B-cell epitope mapping approach. Parasit. Vectors 2020, 13, 1-13. [CrossRef]

8. Garza-Cuartero, L.; Geurden, T.; Mahan, S.M.; Hardham, J.M.; Dalton, J.P.; Mulcahy, G. Antibody recognition of cathepsin L1-derived peptides in Fasciola hepatica-infected and/or vaccinated cattle and identification of protective linear B-cell epitopes. Vaccine 2018, 36, 958-968. [CrossRef]

9. Pérez-Écija, R.A.; Mendes, R.E.; Zafra, R.; Buffonni, L.; Martínez-Moreno, A.; Pérez, J. Pathological and parasitological protection in goats immunised with recombinant cathepsin L1 and challenged with Fasciola hepatica. Vet. J. 2010, 185, 351-353. [CrossRef] 
10. Zafra, R.; Pérez-Écija, R.A.; Buffoni, L.; Pacheco, I.L.; Martínez-Moreno, A.; LaCourse, E.J.; Perally, S.; Brophy, P.M.; Pérez, J. Early hepatic and peritoneal changes and immune response in goats vaccinated with a recombinant glutathione transferase sigma class and challenged with Fasciola hepatica. Res. Vet. Sci. 2013, 94, 602-609. [CrossRef]

11. Zafra, R.; Buffoni, L.; Pérez-Caballero, R.; Molina-Hernández, V.; Ruiz-Campillo, M.T.; Pérez, J.; Martínez-Moreno, Á.; MartínezMoreno, F.J. Efficacy of a multivalent vaccine against Fasciola hepatica infection in sheep. Vet. Res. 2021, 52, 1-9. [CrossRef]

12. Ruiz-Campillo, M.T.; Molina-Hernández, V.; Bautista, M.J.; Pacheco, I.L.; Zafra, R.; Buffoni, L.; Martínez-Moreno, F.J.; MartínezMoreno, A.; Pérez, J. Characterization of dendritic cells and follicular dendritic cells in the hepatic lymph nodes and liver of sheep experimentally infected with Fasciola hepatica. Vet. Res. 2020, 51, 1-10. [CrossRef]

13. Scarcella, S.; Hanna, R.E.B.; Brennan, G.P.; Solana, H.; Fairweather, I. Fasciola hepatica: Histological changes in the somatic and reproductive tissues of liver fluke following closantel treatment of experimentally-infected sheep. Vet. Parasitol. 2016, $215,38-47$. [CrossRef]

14. Hanna, R.E.B.; Moffett, D.; Forster, F.I.; Trudgett, A.G.; Brennan, G.P.; Fairweather, I. Fasciola hepatica: A light and electron microscope study of the ovary and of the development of oocytes within eggs in the uterus provides an insight into reproductive strategy. Vet. Parasitol. 2016, 221, 93-103. [CrossRef] [PubMed]

15. Raadsma, H.W.; Kingsford, N.M.; Suharyanta; Spithill, T.W.; Piedrafita, D. Host responses during experimental infection with Fasciola gigantica and Fasciola hepatica in Merino sheep. II. Development of a predictive index for Fasciola gigantica worm burden. Vet. Parasitol. 2008, 154, 250-261. [CrossRef] [PubMed]

16. Zafra, R.; Buffoni, L.; Martínez-Moreno, A.; Pérez-Écija, A.; Martinez-Moreno, F.J.; Pérez, J. A Study of the Liver of Goats Immunized with a Synthetic Peptide of the Sm14 Antigen and Challenged with Fasciola hepatica. J. Comp. Pathol. 2008, 139, 169-176. [CrossRef]

17. Mendes, R.E.; Zafra, R.; Pérez-Écija, R.A.; Buffoni, L.; Martínez-Moreno, Á.; Tendler, M.; Pérez, J. Evaluation of local immune response to Fasciola hepatica experimental infection in the liver and hepatic lymph nodes of goats immunized with Sm14 vaccine antigen. Mem. Inst. Oswaldo Cruz 2010, 105, 698-705. [CrossRef] [PubMed]

18. Pérez-Caballero, R.; Siles-Lucas, M.; González-Miguel, J.; Martínez-Moreno, F.J.; Escamilla, A.; Pérez, J.; Martínez-Moreno, A.; Buffoni, L. Pathological, immunological and parasitological study of sheep vaccinated with the recombinant protein 14-3-3z and experimentally infected with Fasciola hepatica. Vet Immunol Immunopathol 2018, 202, 115-121. [CrossRef]

19. Mendes, R.E.; Pérez-Écija, R.A.; Zafra, R.; Buffoni, L.; Martínez-Moreno, Á.; Dalton, J.P.; Mulcahy, G.; Pérez, J. Evaluation of hepatic changes and local and systemic immune responses in goats immunized with recombinant Peroxiredoxin (Prx) and challenged with Fasciola hepatica. Vaccine 2010, 28, 2832-2840. [CrossRef]

20. Hanna, R.E.B.; Edgar, H.; Moffett, D.; McConnell, S.; Fairweather, I.; Brennan, G.P.; Trudgett, A.; Hoey, E.M.; Cromie, L.; Taylor, S.M.; et al. Fasciola hepatica: Histology of the testis in egg-producing adults of several laboratory-maintained isolates of flukes grown to maturity in cattle and sheep and in flukes from naturally infected hosts. Vet. Parasitol. 2008, 157, 222-234. [CrossRef]

21. Hanna, R.E.B.; Moffett, D.; Brennan, G.P.; Fairweather, I. Fasciola hepatica: A light and electron microscope study of sustentacular tissue and heterophagy in the testis. Vet. Parasitol. 2012, 187, 168-182. [CrossRef] [PubMed]

22. Hanna, R.E.; Edgar, H.W.J.; McConnell, S.; Toner, E.; McConville, M.; Brennan, G.P.; Devine, C.; Flanagan, A.; Halferty, L.; Meaney, M.; et al. Fasciola hepatica: Histological changes in the reproductive structures of triclabendazole (TCBZ)-sensitive and TCBZ-resistant flukes after treatment in vivo with TCBZ and the related benzimidazole derivative, Compound Alpha. Vet. Parasitol. 2010, 168, 240-254. [CrossRef] [PubMed]

23. Hanna, R. Fasciola hepatica: Histology of the reproductive organs and differential effects of triclabendazole on drug-sensitive and drug-resistant fluke isolates and on flukes from selected field cases. Pathogens 2015, 4, 431-456. [CrossRef] [PubMed]

24. Pérez-Caballero, R.; Buffoni, L.; Martínez-Moreno, F.J.; Zafra, R.; Molina-Hernández, V.; Pérez, J.; Martínez-Moreno, Á. Expression of free radicals by peritoneal cells of sheep during the early stages of Fasciola hepatica infection. Parasit. Vectors 2018, 11, 1-11. [CrossRef] [PubMed]

25. Pérez, J.; Ortega, J.; Moreno, T.; Morrondo, P.; López-Sández, C.; Martínez-Moreno, A. Pathological and immunohistochemical study of the liver and hepatic lymph nodes of sheep chronically reinfected with Fasciola hepatica, with or without triclabendazole treatment. J. Comp. Pathol. 2002, 127, 30-36. [CrossRef]

26. Meeusen, E.; Lee, C.S.; Rickard, M.D.; Brandon, M.R. Cellular responses during liver fluke infection in sheep and its evasion by the parasite. Parasite Immunol. 1995, 17, 37-45. [CrossRef]

27. Martínez-Moreno, A.; Jiménez-Luque, V.; Moreno, T.; Redondo, E.S.H.; De Las Mulas, J.M.; Pérez, J. Liver pathology and immune response in experimental Fasciola hepatica infections of goats. Vet. Parasitol. 1999, 82, 19-33. [CrossRef]

28. Van Milligen, F.J.; Cornelissen, J.B.W.J.; Bokhout, B.A. Protection against Fasciola hepatica in the intestine is highly correlated with eosinophil and immunoglobulin G1 responses against newly excysted juveniles. Parasite Immunol. 1999, 21, 243-251. [CrossRef]

29. Kesik, M.; Jedlina-Panasiuk, L.; Kozak-Cieszczyk, M.; Pucienniczak, A.; Wedrychowicz, H. Enteral vaccination of rats against Fasciola hepatica using recombinant cysteine proteinase (cathepsin L1). Vaccine 2007, 25, 3619-3628. [CrossRef]

30. Cullen, J.M.; Stalker, M.J. Chapter 2-Liver and Biliary System. In Jubb, Kennedy \& Palmer's Pathology of Domestic Animals; Elsevier: Amsterdam, The Netherlands, 2016; Volume 2, pp. 258-352.e1. [CrossRef]

31. Alvarez, J.I.; Londoo, D.P.; Alvarez, A.L.; Trujillo, J.; Jaramillo, M.M.; Restrepo, B.I. Granuloma formation and parasite disintegration in porcine cysticercosis: Comparison with human neurocysticercosis. J. Comp. Pathol. 2002, 127, 186-193. [CrossRef] 
32. Restrepo, B.I.; Alvarez, J.I.; Castaño, J.A.; Arias, L.F.; Restrepo, M.; Trujillo, J.; Colegial, C.H.; Teale, J.M. Brain granulomas in neurocysticercosis patients are associated with a Th1 and Th2 profile. Infect. Immun. 2001, 69, 4554-4560. [CrossRef]

33. Giorgio, S.; Gallo-Francisco, P.H.; Roque, G.A.S.; Flóro e Silva, M. Granulomas in parasitic diseases: The good and the bad. Parasitol. Res. 2020, 119, 3165-3180. [CrossRef]

34. Jaber, J.R.; Zafra, R.; Pérez, J.; Suárez-Bonnet, A.; González, J.F.; Carrascosa, C.; Andrada, M.; Arbelo, M.; Fernández, A. Immunopathological study of parasitic cholangitis in cetaceans. Res. Vet. Sci. 2013, 95, 556-561. [CrossRef]

35. Turk, J.L.; Narayanan, R.B. The Origin, Morphology, and Function of Epithelioid Cells. Immunobiology 1982, 161, $274-282$. [CrossRef]

36. Yamashita, K.; Iwamoto, T. Immunohistochemical observation of lysozyme in macrophages and giant cells in human granulomas. Acta Path. Jap. 1978, 28, 689-695. [CrossRef] [PubMed]

37. Spector, W.G. Epithelioid cells, giant cells, and sarcoidosis. Ann. N. Y. Acad. Sci. 1976, 278, 3-6. [CrossRef]

38. Keshav, S.; Chung, P.; Milon, G.; Gordon, S. Lysozyme is an inducible marker of macrophage activation in murine tissues as demonstrated by in situ hybridization. J. Exp. Med. 1991, 174, 1049-1058. [CrossRef] [PubMed]

39. Basika, T.; Muñoz, N.; Casaravilla, C.; Irigoín, F.; Batthyány, C.; Bonilla, M.; Salinas, G.; Pacheco, J.P.; Roth, J.; Durán, R.; et al. Phagocyte-specific S100 proteins in the local response to the Echinococcus granulosus larva. Parasitology 2012, 139, 271-283. [CrossRef] [PubMed]

40. Van Gorp, H.; Delputte, P.L.; Nauwynck, H.J. Scavenger receptor CD163, a Jack-of-all-trades and potential target for cell-directed therapy. Mol. Immunol. 2010, 47, 1650-1660. [CrossRef]

41. Verreck, F.A.W.; de Boer, T.; Langenberg, D.M.L.; van der Zanden, L.; Ottenhoff, T.H.M. Phenotypic and functional profiling of human proinflammatory type- 1 and anti-inflammatory type- 2 macrophages in response to microbial antigens and IFN- $\gamma$ - and CD40L-mediated costimulation. J. Leukoc. Biol. 2006, 79, 285-293. [CrossRef]

42. Barros, M.H.M.; Hauck, F.; Dreyer, J.H.; Kempkes, B.; Niedobitek, G. Macrophage polarisation: An immunohistochemical approach for identifying M1 and M2 macrophages. PLoS ONE 2013, 8, 1-11. [CrossRef] [PubMed]

43. Melzi, E.; Rocchi, M.S.; Entrican, G.; Caporale, M.; Palmarini, M. Immunophenotyping of Sheep Paraffin-Embedded Peripheral Lymph Nodes. Front. Immunol. 2018, 9, 2892. [CrossRef] [PubMed]

44. Fernández, M.; Benavides, J.; Castaño, P.; Elguezabal, N.; Fuertes, M.; Muñoz, M.; Royo, M.; Ferreras, M.C.; Pérez, V. Macrophage Subsets Within Granulomatous Intestinal Lesions in Bovine Paratuberculosis. Vet. Pathol. 2017, 54, 82-93. [CrossRef] [PubMed]

45. Cabanelas, E.; Panadero, R.; Fuertes, M.; Fernández, M.; Benavides, J.; López, C.; Pérez-Creo, A.; Díaz, P.; Morrondo, P.; DíezBaños, P.; et al. Histological and immunohistochemical characterization of Hypoderma lineatum (Diptera: Oestridae) warbles. Vet. Parasitol. 2015, 212, 361-367. [CrossRef]

46. Adler, L.N.; Jiang, W.; Bhamidipati, K.; Millican, M.; Macaubas, C.; Hung, S.C.; Mellins, E.D. The other function: Class II-restricted antigen presentation by B cells. Front. Immunol. 2017, 8, 1-14. [CrossRef]

47. ten Broeke, T.; Wubbolts, R.; Stoorvogel, W. MHC class II antigen presentation by dendritic cells regulated through endosomal sorting. Cold Spring Harb. Perspect Biol. 2013, 5, 1-21. [CrossRef]

48. Romero-Palomo, F.; Risalde, M.A.; Molina, V.; Sánchez-Cordón, P.J.; Pedrera, M.; Gómez-Villamandos, J.C. Immunohistochemical Detection of Dendritic Cell Markers in Cattle. Vet. Pathol. 2013, 50, 1099-1108. [CrossRef]

49. De Saint-Vis, B.; Vincent, J.; Vandenabeele, S.; Vanbervliet, B.; Pin, J.J.; Aït-Yahia, S.; Patel, S.; Mattei, M.G.; Banchereau, J.; Zurawski, S.; et al. A novel lysosome-associated membrane glycoprotein, DC-LAMP, induced upon DC maturation, is transiently expressed in MHC class II compartment. Immunity 1998, 9, 325-336. [CrossRef]

50. Escamilla, A.; Zafra, R.; Pérez, J.; McNeilly, T.N.; Pacheco, I.L.; Buffoni, L.; Martínez-Moreno, F.J.; Molina-Hernández, V.; Martínez-Moreno, A. Distribution of Foxp3+ T cells in the liver and hepatic lymph nodes of goats and sheep experimentally infected with Fasciola hepatica. Vet. Parasitol. 2016, 230, 14-19. [CrossRef]

51. Pacheco, I.L.; Abril, N.; Zafra, R.; Molina-Hernández, V.; Morales-Prieto, N.; Bautista, M.J.; Ruiz-Campillo, M.T.; Pérez-Caballero, R.; Martínez-Moreno, A.; Pérez, J. Fasciola hepatica induces Foxp3 T cell, proinflammatory and regulatory cytokine overexpression in liver from infected sheep during early stages of infection. Vet. Res. 2018, 49,1-10. [CrossRef]

52. McNeilly, T.N.; Rocchi, M.; Bartley, Y.; Brown, J.K.; Frew, D.; Longhi, C.; McLean, L.; McIntyre, J.; Nisbet, A.J.; Wattegedera, S.; et al. Suppression of ovine lymphocyte activation by Teladorsagia circumcincta larval excretory-secretory products. Vet. Res. 2013, 44, 70. [CrossRef] [PubMed] 